\title{
CIENCIAS SOCIALES EMPÍRICAS Y BIOÉTICA Reflexiones de circunstancia y un epílogo para latinoamericanos
}

\author{
Fernando Lolas Stepke*
}

Resumen: Este artículo destaca la necesidad de armonizar la reflexión bioética con los resultados de las ciencias sociales empíricas, definidas como aquellas disciplinas que describen y predicen el comportamiento de individuos y grupos y aspiran a formular principios generales de causalidad. El cultivo de tales disciplinas enriquece los aspectos descriptivos y prescriptivos de las afirmaciones sobre lo bueno y lo malo y permite matizar el juicio moral. La meta es analizar la influencia del contexto sobre las decisiones morales y someter a estudio empírico la misma práctica de la bioética. Se concluye con algunas observaciones sobre la conveniencia de desarrollar una bioética latinoamericana con solvencia intelectual y la posibilidad de insertarse creativamente en el pensamiento global.

Palabras clave: Ciencias sociales, bioética, conducta, grupo, sociedad

\section{EMPIRICAL SOCIAL SCIENCES AND BIOETHICS: Some reflections and an afterthought for Latin Americans}

\begin{abstract}
This paper emphasizes the need to integrate bioethical reflection with the results of empirical social sciences, defined as those disciplines which describe and predict behavior of individuals and groups and strive at general causality principles. Cultivating such disciplines enriches descriptive and prescriptive aspects of assertions regarding what is right and wrong and permits modulation of moral judgement. The goal is to analyze the influence of context on moral decision making and to submit to empirical study even the practice of bioethics. Finally, some observations are put forward on the convenience of developing a Latin American bioethics intellectually respectable and with the possibility of placing itself creatively in global thinking.
\end{abstract}

Keywords: Social sciences, bioethics, behavior, group, society

\section{CIÊNCIAS SOCIAIS EMPÍRICAS E BIOÉTICA: Reflexões da circunstância e de um epilogue para os latinoamericanos}

Resumo: Este artigo destaca a necessidade de harmonizar a reflexão bioética com os resultados das ciências sociais empíricas, definidas como as disciplinas que descrevem e predizem o comportamento de indivíduos e grupos e pretendem formular princípios gerais de causalidade. O cultivo de tais disciplinas enriquece os aspectos descritivos e prescritivos das afirmações sobre o bom e o mal e permite matizar o juízo moral. A proposta é analisar a influência do tema sobre as decisões morais e submetê-las a estudo empírico pelo modelo da bioética. Apresenta como conclusão algumas observações sobre a conveniência de se desenvolver uma bioética latino-americana com crédito intelectual, assine como a possibilidade de inserí-la criativamente no pensamento global.

Palavras chave: Ciências sociais, bioética, conduta, grupo, sociedade

\footnotetext{
* Profesor Titular de la Facultad de Medicina de la Universidad de Chile. Director del Programa Regional de Bioética OPS/OMS Correspondencia: lolasf@chi.ops-oms.org
} 


\section{Ciencias sociales empíricas: una delimitación conceptual}

Bajo la denominación genérica de ciencias sociales empíricas agrupo todas aquellas disciplinas intelectuales que se ocupan del comportamiento y la interacción de individuos y colectivos humanos. En muchos sentidos puede ser reemplazada por la expresión ciencias humanas. Corresponde en realidad a la clásica categoría de las "nuevas humanidades", que complementaron las disciplinas de la literatura, el arte y la historia desde comienzos del siglo XIX y que se abocaron a la descripción, explicación y predicción del comportamiento humano en sus diversos ámbitos(1).

Con el apelativo empírico deseo indicar que el modo preferido de alcanzar certidumbres y las formas argumentativas usadas para obtener prestigio profesional derivan de experiencias sensoriales regladas y metódicas, usualmente traducidas en guarismos y cantidades que expresan el carácter público, falseable y refutable de las evidencias y la posibilidad de generar leyes de regularidad para lo estudiado.

Cuando esta intención formadora de leyes generales ("nomotética") no se alcanza o no se espera, el impulso idiográfico o individualizador no deja por ello de estar orientado a la predicción de regularidades que agoten la descripción de lo observado en distintos contextos.

Desde sus albores, la filosofía práctica ha tenido relación con la descripción del comportamiento, agregando las connotaciones de deseable/no deseable o bueno/malo. El grado en que la teorización filosófica ha tomado en cuenta las aportaciones científicas es un atributo de escuela. Así, hay tendencias éticas en las cuales prima el análisis de las consecuencias y por ende la responsabilidad del agente moral o la influencia de la tradición y la cultu- ra. Otras, en cambio, privilegian el desarrollo sistemático y obligatorio de construcciones axiomáticas que se traducen en deberes. Diversos conceptos y antinomias recogen esta dualidad: deontología versus teleología, Gesinnungsethik versus Verantwortungsethik (ética de convicciones versus ética de responsabilidad), ética teórica versus ética empírica, por sólo citar algunos(2). El punto central es que la consideración de las certidumbres derivadas de la experiencia y el experimento varía en los distintos autores que cabe adscribir a la tradición "etográfica", o productora de textos éticos, en la conciencia occidental.

La bioética puede concebirse como una forma de ética de carácter dialógico y contenido "contingencial". Esto quiere decir que su forma preferida de argumentación es deliberativa y su campo de intereses abierto a nuevos desafíos temáticos generados por cambios en las condiciones de vida de la especie humana. Como tales cambios se han debido en medida importante a la artificialidad introducida por la praxis de las tecnociencias y sus derivaciones, la bioética está ligada a la acción humana en su vertiente de invención e innovación. Aunque la finalidad del discurso sea universal, la bioética sobrepasa las tradicionales preguntas de la ética filosófica clásica (monológica), incrementa el perspectivismo de los diferentes actores y agentes morales y recibe la impronta del quehacer y la reflexión de las tecnociencias $(3,4)$.

Estas precisiones permiten justificar la pregunta por las relaciones entre bioética y datos de las ciencias sociales empíricas.

\section{Relaciones entre bioética y ciencias sociales empíricas: justificación de la pregunta}

La pregunta se justifica en la necesidad de reclamar originalidad, universalidad y legitimidad para las reflexiones, decisiones y 
recomendaciones apoyadas por la racionalidad bioética. Toda decisión y toda conclusión están influidas por el contexto en que se generan(5). Desconocerlo impide matizarlas o relativizarlas. Esta matización podría prevenir el divorcio, ya habitual y esperable, entre reflexión filosófica y asuntos prácticos. Así la bioética puede transformarse en una auténtica herramienta para la convivencia significativa entre personas, ideologías, grupos y culturas. De allí lo apropiado de hablar de la bioética como de una "disciplina pontifical", pues tiende puentes "entre" y adquiere un carácter "intersticial", fuera de las densificaciones disciplinarias de la modernidad. La fuerza de esta intersticialidad deriva de dar presencia a las confusas nociones de interdisciplinariedad que antecedieron, en diversas formas, a la eclosión del discurso bioético (movimiento psicosomático, estudios sociales de las ciencias, holismos médicos, por citar algunos ejemplos). La tesis sostenida aquí es que lo bioético no es sino la concreción de esa dimensión intersticial y "covalente", inspiradora de diálogo y puente, presente en todo trabajo humano y la restauración del "mundo de la vida" (Lebenswelt) como legítimo punto de partida "existencial" para las preguntas morales, que se abocan a proponer, justificar y aplicar normas sociales.

Proponer, justificar y aplicar normas son tareas reflexivas y de principiación. Pues toda norma ha de estar racionalmente concebida y expresada y ha de basarse en principios comprensibles y explicables. Algunas normas derivan de creencias y suelen ser implícitas. Otras, explícitas, son producto de la imposición de una voluntad o de la deliberación consensual. Unas y otras pueden ser sometidas al examen dialógico y a la "negociación". Esta palabra se usa aquí despojada de todo sesgo peyorativo, como parecería si implicase renunciar a las propias convicciones en vista de ganancias. Solamente indica la posibilidad de transacciones argumentativas para decidir cau- ces y cursos de acción. Una nueva casuística, cuyas "circunstancias" se ampliarían a los hallazgos y problemas de las ciencias sociales y humanas, será necesaria en los años venideros y ampliará el tipo y la magnitud de los "casos de conciencia" que trabajó la casuística clási$\mathrm{ca}(6)$.

\section{Indidivuo, Gemeinschaft y Gesellschaft}

Es razonable explorar el ámbito discursivo de las disciplinas caracterizadas como ciencias sociales empíricas. Ninguna designación es apropiada para englobar la psicología individual, la antropología, la economía, la sociología y otras cuyo estatuto científicoempírico ha sido puesto en duda, como la historia. No es el método hipotético-deductivo ni la epistemología lo que se toma en cuenta para agruparlas aquí sino su vinculación al comportamiento humano. Como etología caracterizó John Stuart Mill una ciencia del carácter, designación etimológicamente correcta pero no utilizable debido a que el término se empleó para describir el estudio comparado del comportamiento.

Es una comprobación frecuente, ya considerada un hecho (fact), que en las realidades llamadas humanas -aquellas accesibles a la introspección y la palabra o el texto- lo real es lo mudable. En cambio en la naturaleza no humana lo real es lo inmutable. Por tanto, la variabilidad y la pluralidad son precondiciones de todo teorizar, que hacen difícil la formulación o defensa de principios inmutables. Estos derivan de una constricción, deliberada o accidental, de la conciencia y la vivencia de infalibilidad que hace de la verdad la adecuación de lo pensado a lo experimentado.

Poco se toma en cuenta, en la literatura filosófica, el tema de las diferencias individuales, central en la ciencia psicológica y fundamento de la noción de personalidad. Suele 
reconocerse la impronta de los rasgos, disposiciones permanentes, y los estados, condiciones transitorios, en la cognición y la atención, pero este tipo de estudios estaría fuera de lugar en una discusión técnica de filosofía pura o práctica. A lo sumo, en casos extremos como Nietzsche o Descartes, se podría aceptar la explicación psicológica, en relación con afectos, propensiones o hábitos, para debatir sobre contenidos de la reflexión o sobre el peso relativo de los argumentos. Ni siquiera la especulación psicoanalítica o la investigación del inconsciente, con su fuerte impacto en la cultura europea, pasa de tener un papel menor en el análisis del texto filosófico (en tanto documento técnico y no como expresión literaria).

Carácter algo menos marginal, pero siempre de excepción, tiene la consideración de categorizaciones como cultura, raza, grupo social o religión en las formulaciones filosóficas de principios, en los que se supone palpita lo humano eterno y universal. No es de extrañar que sea la religión y más en general, la creencia, la fuente principal de certidumbres sobre lo deseable y bueno, pues la creencia, a diferencia de las ideas, se impone por su solo existir (Ortega y Gasset decía que en las creencias "se está", en cambio las ideas "se tienen", con lo que quería significar que el substrato creencial no se formula explícitamente ni se somete a prueba o refutación y pertenece a un orden de certezas distinto del de las ideas). Muchas de las categorías moduladoras de la reflexión son a su vez creenciales (la desprestigiada noción de raza, por ejemplo), de modo que ellas requieren detenido examen antes de aceptarse como válidas influencias sobre las convicciones personales o los contenidos de la argumentación. Se encuentran desacreditadas nociones como la "personalidad modal" o el "carácter nacional" para explicar la recurrencia de temas o la presencia de estilos de argumentación, pero en la vida diaria siguen teniendo vigor nociones de suyo infun- dadas, tales como "el temple (o espíritu) democrático" o la "honestidad intelectual" que pueden emplearse no solamente para describir sino también para explicar y aún legitimar determinadas posturas filosóficas o morales.

Es justamente la explicitación de tales soterradas y no reconocidas inlfuencias una de las tareas de la indagación que aquí llamamos social empírica. No para refutar, ni siquiera para alterar, el discurso bioético universal o las convicciones personales, sino para otorgarles la dimensión de la profundidad y la multidimensionalidad de los ecos que producen los condicionantes personales y colectivos. Como decía Bacon, los "idola" que perturban el pensar y que también se hacen presentes en el sentir, el desear y el preferir.

Una tensión ética fundamental, aquella entre lo individual y lo colectivo, entre lo particular y lo general, entre la persona y la sociedad, requiere ser formulada en distintos registros. Por ejemplo, no toda la teorización "social" o sobre grupos tiene la misma apariencia ni se basa en las mismas construcciones hipotéticas. Es relevante, por ejemplo y sólo como ejemplo, la diferencia entre las comunidades pequeñas donde las relaciones sociales son "cara a cara" y constituyen un fin en sí y las megasociedades en las cuales la prosecución de fines individuales usa el marco de resonancia de la gran comunidad y las relaciones sociales son medios y no fines. Dase el nombre técnico de Gemeinschaft a las primeras y Gesellschaft a las segundas. Así como ésta, hay muchas otras distinciones, entre metódicas y substantivas, que es necesario considerar en el análisis.

La "polifonía moral" de las sociedades civiles es también una "polifonía epistémica" que urge considerar conjuntamente en la construcción de la imaginación moral societaria e individual. 


\section{Racionalidades descriptiva, prescriptiva y normativa}

La intención permite demarcar ámbitos discursivos, pues las intenciones van asociadas a intereses (Inter-Esse, lo que está "entre" los seres, puede ser el fundamento de su vinculación). Un interés artístico puede asociarse a un interés científico o comercial y desarrollarse en dirección a racionalidades distintas, antagónicas o complementarias. Así, el examen de la conducta humana puede tener una finalidad descriptiva y pronóstica, como en el caso del diagnóstico psicológico. Pero también puede tener finalidad prescriptiva, como en las normas sociales, o normativa, cuando aspira a la perennidad y la permanencia del ordenamiento jurídico.

Aunque las ciencias sociales empíricas pudieran no tener lo prescriptivo dentro de su cometido, inevitablemente el "viraje expertocrático" de las sociedades modernas hace que lo dicho por los expertos (o los científicos) tenga el imperio de lo deseable o lo obligatorio. El origen del poder del saber es múltiple, pues se basa en potencia explicativa, capacidad predictiva, rigor, atractivo estético y ascendiente moral. Ya asociar lo correcto, o apropiado, con lo bueno, o deseable, tiene la connotación mixta, técnica y moral, con que la tecnociencia contemporánea rige y regimenta la vida individual y comunitaria. Una mirada objetivante es una "mirada interesada" en un sentido distinto a como puede serlo una mira poética o una religiosa. Su legitimidad para el discurso bioético debe ser materia de permanente examen, pero su realidad es innegable como dato de entrada.

\section{Interfaces bioética / ciencias sociales empí- ricas: Modos de relación}

No es simple la construcción de las áreas de contacto entre intereses e intenciones en el espacio multidimensional de las conciencias. Por de pronto, existiría una sociología "en" la bioética así como hay una bioética "en" la sociología o la psicología o cualquier otra ciencia. Mas también es concebible tratar la bioética como una práctica social y hacer, por ejemplo, una sociología "de" la bioética o una psicología "de" quienes usan el discurso bioético.

El constructivismo de las disciplinas contemporáneas permite prever que deberán diseñarse para sostener o al menos no contradecir la pluralidad de intereses y miradas que acepta el mundo de la vida y no se agotan con la multiplicación infinita de las racionalidades que han de domeñarlo o concebirlo. Una ciencia social postbioética no podría ser la misma que una prebioética. La emergencia del nuevo discurso modifica la intensidad y la posición relativa de todos los demás en sus contenidos y en su influencia social. Del mismo modo, podría decirse que cultores de la bioética procedentes de distintas áreas pueden fructíferamente engendrar productos distintos. En la riqueza de su diversidad pueden contener las bases de su aceptación, de su utilidad y del goce de su presencia.

\section{"Tools shape thought"}

La expresión "las herramientas dan forma al pensar" es literal, no metafórica. Las útiles ficciones de las ciencias son posibles por el desarrollo de instrumentos capaces de darles concreción como lectura de cifras, valores calculables, imágenes visibles o palabras audibles. Nada de eso es posible sin un desarrollo instrumental que haga visible lo invisible, "haga objeto" de observación las experiencias sensoriales o los cambios del entorno.

Las herramientas pueden usarse para generar informaciones y datos. También hay 
herramientas para articular y organizar datos. Las informaciones cuya arquitectura constituye el conocimiento, permiten definir éste como información organizada en torno a un interés social o una intención.

Tales herramientas pueden ser físicas o conceptuales. Se precisan distintas disciplinas (discursos que crean los objetos de los cuales hablan) para desarrollar herramientas apropiadas para ese fin. Nuevos canales de información, nuevos "ojos" y "oídos", formas novedosas de generar datos e informaciones y construir conocimientos.

Las aquí llamadas ciencias sociales empíricas tienen un papel en el discurso bioético difícilmente subestimable. Pues tal discurso no replica simplemente la ética filosófica ni recapitula la moral profesional. Imbrica, en realidad, las nuevas humanidades con lo prescriptivo y lo normativo de la conciencia moral y la imaginación societaria. No puede ignorar las aportaciones del discurso, ya establecido, de las ciencias humanas y sociales, que correctamente integradas al corpus nocional de la modernidad, complementarán el tradicional papel compensatorio y dador de sentido de las humanidades clásicas y de las llamadas ciencias del espíritu

\section{El contexto latinoamericano}

Es casi de rigor, en nuestra circunstancia social e histórica, reconocer la impronta del contexto en el cual trabajamos y pensamos. Hace muchos años, una interesante polémica entre el intelectual peruano Augusto Salazar Bondy y el escritor mexicano Leopoldo Zea, me hizo reflexionar en esa entelequia que denominamos americanidad(7). La pregunta de Salazar Bondy era si existe una filosofía americana. La contestaba negativamente, indican- do que la dimensión teórica de la reflexión quedaba ajena a nuestros pueblos. Por su parte, Leopoldo Zea indicaba que la filosofía americana era "filosofía sin más". Decía que los griegos, cuando filosofaron, no se propusieron hacer filosofía "griega" sino simplemente preguntar, con ingenuidad y rigor, aquello que los seres humanos siempre han preguntado. Por lo tanto, aparte de ser pregunta vana, la de Salazar Bondy conduce a un absurdo dilema: o se construye la filosofía americana con los productos "naturales" de estas tierras (si se supiera cuales son) o se renuncia a decir que tenemos filosofía.

Podrá parecer absurdo que los latinoamericanos hayan siempre tenido esa comprobación de su ser derivado como vergonzante. Las respuestas han sido combativos indigenismos, pintorescos rechazos de todo lo "no latinoamericano" o ingenuas propuestas para reinventar la rueda y la pólvora. Podrá ser argumento ya perimido, pero sin embargo reaflora bajo las más diversas apariencias. Algunos adalides del localismo indigenista creen hacer un servicio a la causa rechazando por foránea toda influencia que no provenga de ellos mismos. No precisan aprender, no precisan dialogar, no precisan debatir. Otros sabios autóctonos, no menos perjudiciales, mientras dicen lo mismo, tratan de afianzar posiciones en el "gran mundo" de la ciencia y la filosofía cosmopolitas y no desdeñan migajas de reconocimiento que de allí provienen.

En esta materia, como en otras, los medios no son justos ni lo mejor. Tarea práctica a la vez que teórica, insertar el pensamiento original de Latinoamérica en el concierto de las voces universales no puede consistir en negar lo universal y cultivar ese peligroso aislamiento a que nuestras instituciones de caudillos pudieran impulsarnos. Una simple mirada histórica revela que el caudillismo americano 
no es sólo fenómeno político sino también intelectual. Las formas adoptadas por nuestras cofradías a veces semejan pandillas, otras grupos dedicados al matonaje intelectual, en ocasiones devotos seguidores de sedicentes profetas.

La seriedad que exige la construcción de una bioética latinoamericana obliga a escuchar, incluso examinar, tales argumentos. Las ciencias sociales empíricas, en el sentido aquí expuesto, deben contribuir a aclarar esos procesos sociales que son el rechazo irracional a lo foráneo o su acrítica y mansa aceptación. Un papel de las organizaciones de la cultura debe ser generar condiciones para un diálogo fructífero. Sus integrantes no deben dejarse pro- vocar por las afirmaciones prepotentes de voceros de cualquier convicción sino contribuir a fundamentar la noción de que substancia, contexto y circunstancia de la reflexión se justifican sólo si ésta está bien hecha, si es rigurosa, si "vale la pena", hágala quien la haga.

Cuando los angloparlantes y otros europeos decidan, como hizo Kölliker para poder leer a Cajal, aprender nuestra lengua podremos decir que, efectivamente, lo que estamos diciendo también para ellos vale la pena y no es un mero ejercicio de condescendencia con nuestras locales ambiciones de prestigio. Precondición para eso es saber de qué hablamos y tener una inserción razonada y razonable en el concierto de las voces bioéticas.

\section{Referencias}

1. Piaget J, Mackenzie WJ, Lazarsfeld PF et al. Tendencias de la investigación en las ciencias sociales. Madrid: Alianza/UNESCO; 1973.

2. Weber M. Economía y sociedad. 2a ed. México DF : Fondo de Cultura Económica; 1999.

3. Lolas F. Bioética. El diálogo moral en las ciencias de la vida. $2^{\mathrm{a}}$ ed. Santiago de Chile: Editorial Mediterráneo; 2001.

4. Lolas F. Temas de Bioética. Santiago de Chile: Editorial Universitaria; 2002.

5. Nichter M, Lock M, eds. New Horizons in Medical Anthropology. London \& New York: Routledge; 2002.

6. Kleinman A. Moral experience and ethical reflection: can ethnography reconcile them ? A quandary for "The new bioethics". Daedalus, Fall 1999, pp. 69-97.

7. Lolas F. Sobre americanidad (1974). En: Lolas F. Notas al Margen. Ensayos. Santiago de Chile: Editorial Cuatro Vientos; 1985. 